Equinoccio. Revista de psicoterapia psicoanalítica, 2(2), julio-diciembre 2021, pp. 159-177.

ISSN: 2730-4833 (papel), 2730-4957 (en línea). DOI: doi.org/10.53693/ERPPA/2.2.9.

\title{
DESAFIOOS E INTERVENCIONES EN LA CLIINICA CON PERSONAS CON DISCAPACIDAD CONVERSACIÓN CON JORGE CANTIS
}

\author{
Ana Mosca \\ Asociación Uruguaya de Psicoterapia Psicoanalítica \\ Montevideo, Uruguay \\ Correo electrónico: anamosca@yahoo.com \\ ORCID: 0000-0002-7462-943X

\section{María Elisa Domínguez} \\ Asociación Uruguaya de Psicoterapia Psicoanalítica \\ Montevideo, Uruguay \\ Correo electrónico: maelisadominguez@gmail.com \\ ORCID: 0000-0001-7821-9422
}


Jorge G. Cantis es licenciado en Psicología y psicoanalista. Entre otras áreas clínicas, se destaca por una extensa especialización en el área de la discapacidad, particularmente en la psicoterapia con niños y adolescentes.

Es miembro de la Asociación Argentina de Psiquiatría y Psicología de Infancia y Adolescencia (ASAPPIA), institución dentro de la cual ha desempeñado numerosas responsabilidades, incluida la presidencia. Desarrolla una importante labor docente dentro de la mencionada asociación, así como en otras universidades de Argentina. En efecto, ha sido coordinador del área de Discapacidad de ASAPPIA y director de formación del posgrado Discapacidad: Entramados Singulares, Familiares y Sociales, de la misma institución. También es director de la carrera de especialización Discapacidad: Campos de Intervención: Subjetividad e Interdisciplina (Colegio de Psicólogos de Mar del Plata), director de la carrera de especialización Discapacidad: Perspectivas Subjetivas e Intersubjetivas (Colegio de Psicólogos de Bahía Blanca), profesor titular de Psicología III en la licenciatura de Fonoaudiología (Facultad de Medicina, Universidad de Buenos Aires), profesor titular en la carrera de especialización en Psicología Clínica de la Discapacidad (Facultad de Psicología, Universidad de Buenos Aires) y profesor titular de Abordaje Psicosocial de las Discapacidades en la maestría en Problemas y Patologías del Desvalimiento (Universidad de Ciencias Empresariales y Sociales). Asimismo, es supervisor institucional en centros educativos terapéuticos e instituciones de educación especial.

Ha publicado artículos y libros sobre temáticas de su especialidad. Entre ellos sobresalen: Vinculos, subjetividades y malestares contemporáneos, compilado por Ilena Fischer y editado por Entreideas en octubre del 2020, en el que participó en calidad de coautor; y Discapacidad: reflexiones psicoanaliticas e intervenciones posibles. Familias-subjetividad-terapeutas, editado en marzo del 2020 por Ricardo Vergara, del cual fue autor. 


\section{INTRODUCCIÓN}

El tema de la discapacidad constituye un desafío contemporáneo para las sociedades que, como la nuestra, aspiran a una vida en democracia. Algunas estimaciones demográficas sitúan en un 10\% el porcentaje de ciudadanos que evidencian mayor o menor compromiso en su capacidad de autonomía. Ha de ser una labor colectiva el desarrollar en cada integrante de esa comunidad la sensibilidad y la comprensión que sustenten una genuina integración social. El rol de la educación está en la base de estos procesos, la inclusión no será suficiente si no se acompaña de una microlabor que genere un espíritu de integración como pilar ético que la habilite.

Desde comienzos del siglo xx, nuestro país fue faro en América Latina como pionero en avances de la educación especial, que es imprescindible como complemento a una política de inclusión. Desde 1917 existieron las llamadas «clases diferenciales», que desarrollaban una pedagogía remedial. En 1949 se fundó la primera Escuela de Recuperación Psíquica. No obstante, a partir de 1980 se ha producido cierto estancamiento que ha de ser revisitado y que demanda intervenciones interdisciplinarias. En 2006 la Organización de las Naciones Unidas promulgó la Convención Internacional de los Derechos de las Personas con Discapacidad, ratificada por nuestro país en 2008. Evidentemente la normativa no es suficiente: se necesita una labor de educación en derechos humanos que fundamente una vida comunitaria en salud mental.

En el pensamiento psicoanalítico se ha producido una evolución y se ha ampliado el criterio de analizabilidad desde una descalificación 
desesperanzada hacia una mirada habilitante, en la cual, como decía Alicia Fernández, «el verbo creer y el verbo crear, que en primera persona del singular se conjugan de modo idéntico, habiliten una sinergia recíproca». Es desde estas reflexiones que introducimos a nuestro entrevistado, Jorge Cantis. Él ha sido un promotor, un mediador, un abanderado en la lucha por visibilizar la mirada desesperanzada sobre las personas que evidencian discapacidad.

En su libro Discapacidad: reflexiones psicoanaliticas e intervenciones posibles. Familias-subjetividad-terapeutas (2020) transmite varias afirmaciones contundentes que provienen de su práctica clínica, docente y académica. Sostiene que el diagnóstico suele vivirse como estigma, como sentencia, y denuncia el sentimiento de compasión que encubre el desprecio. Encara frontalmente los desafíos para la labor analítica al develar psicodinamismos en lo intrapsíquico, en lo interpersonal y en lo institucional. Sugiere también intervenciones, buenas prácticas, sustentadas en cuatro décadas de labor en el campo.

Ha sido, además, un amigo consecuente de AUDEPP, presente en todos nuestros congresos, especialmente en la temática de la discapacidad de nuestra agenda científica. 


\section{LA CONVERSACIÓN}

Jorge, tú adviertes las precauciones que han de tomarse en el momento de comunicar el diagnóstico a la familia para que no se viva como estigma o como sentencia. ¿Cómo intervenir en el momento del diagnóstico?

Muy interesante la pregunta porque en el campo de la discapacidad los papás vienen muy abrumados con el diagnóstico o con el no-diagnóstico. La categoría diagnóstica, si bien le pone un nombre al niño, abandona la subjetividad. El niño es un down, un ciego, un sordo, y pierde la singularidad. Vivimos en tiempos de internet, entonces lo primero que pregunto es qué googlearon, qué buscaron, porque el problema del googleo es que, aunque pueda ser muy exacta la descripción de la patología, no contempla la singularidad, la subjetividad. Lo que intento hacer como psicoterapeuta y psicoanalista es rescatar, dentro del diagnóstico, lo diferencial. Ver qué es lo diferente. Dos niños con el mismo diagnóstico tienen evoluciones diferentes según el contexto sociofamiliar. Hay que pensar la discapacidad desde una mirada social y de derechos. Se cambió el paradigma no solamente de la inclusión-exclusión, sino además la mirada social y familiar. Depende de cómo es investido libidinalmente por la madre y el padre, y ahí rescatamos al niño. El diagnóstico nos sirve para planificar el tratamiento, pero tenemos que entender qué le pasa al niño. Hay que ver, luego del diagnóstico, si la familia sigue viéndolo como «Pablito» o como «el down». Puede ser que en la comunidad ya no sea «la Familia González», sino «la familia del down». Tenemos que trabajar para que el diagnóstico no cristalice la subjetividad y el vínculo.

¿Esto ejemplificaría lo que tú llamas neurosis traumática familiar? También citas a Maldavsky. 
Maldavsky fue mi profesor y supervisor por más de treinta años. Se basa en el concepto de neurosis traumática de Freud. Él profundiza ese concepto y sus variedades en la neurosis traumática familiar en relación con el desvalimiento. Hay dos neurosis: la neurosis traumática individual, que es la que padece el niño o el adolescente con discapacidad, y la neurosis traumática familiar, que produce efectos diferentes en cada uno de los integrantes de la familia y de la familia extendida. Hay abuelas que cumplen una función importante, muchas veces tengo entrevistas con abuelas porque son las que los que acompañan a sus nietos en los tratamientos. Ahora en pandemia es más complicado, ahora se agrega el duelo por las abuelas que no están, estos niños que tienen tanta pregnancia.

Entonces, neurosis traumática familiar en tanto la discapacidad produce efectos devastadores en la familia, no como desgracia sino como impacto. Ninguna familia está preparada. La familia se va preparando de acuerdo a la salud mental de cada integrante. Hay familias más resilientes y otras que siguen duelando al hijo, extrañan aquello que nunca existió. Abordo la discapacidad desde el lugar del trauma, no solamente del duelo. ¿Trauma por qué? Porque es la multiplicidad de incitaciones endógenas y exógenas que el familiar tiene que procesar. Lo que dice internet, lo que dice la sociedad. Por ejemplo, la familia tiene mucho amor por este hijo: «Tengo un hijo con síndrome de down y lo quiero»; pero cuando llega la escolaridad empieza el trauma otra vez: lo incluyen, no lo incluyen, los cumpleaños. Entonces siempre está la discapacidad a merced de la resignificación de lo traumático.

En pandemia se complicó. Pasaron a estar todos guardados en casa, sin escuelas, niños que estaban muy estimulados. Entonces, el terror de la familia es qué hacemos con estos niños sin actividad. El niño con más recursos podía entretenerse. Lo que tenemos que ir viendo es la capacidad adaptativa que tiene la familia —en el buen sentido de la 
palabra - frente a lo traumático, porque siempre algo se resignifica, se resignifica todo el tiempo.

\section{¿Cómo resistir al dolor furioso e impotente?}

Trabajo mucho el tema del agotamiento profesional y los efectos contratransferenciales, claves en cualquier clínica, pero especialmente en esta, que es una clínica donde corremos el riesgo de la frustración, entre la frustración y la omnipotencia. Hay mucho de omnipotencia para querer trabajar con estos niños, pero también hay mucha frustración y obstáculo. Por eso, hay que trabajar con esto: uno queda como impotentizado, con mucha impotencia frente a la imposibilidad. Vemos cómo la impotencia es aquello que no fue dicho. Muchas veces uno tiene que poder — a la manera kleiniana, por así decirlo— darse cuenta de los sentimientos que nos genera esa escena. Los adolescentes tienen su timing. En el encuentro virtual aparecen tarde y yo les comento que me molesta que lleguen tarde a la sesión, porque es tiempo que perdemos. En vez de enojarme, les digo lo que yo siento, les hablo de mi sentir. Les digo que armo el zoom, pero que estar 20 minutos esperando, no. No les va a servir la terapia. No le aviso a la mamá, lo trabajo con él. Considero que él tiene herramientas.

\section{Frente al niño con discapacidad, ¿cómo operar en la delgada línea entre desahuciarlo y el furor curandis?}

Tiene que ver con dos cuestiones: desahuciar al paciente es cuando el terapeuta se quedó sin rumbo, está perdido, no sabe para dónde ir. Como esta es una clínica que tiene mucho que ver con la monotonía, hay que tratar de que el terapeuta capte lo diferencial en esa monotonía. En una supervisión reciente, una colega decía que se cansaba mucho con 
estos niños, por eso hablo de una contratransferencia somática, uno pone el cansancio en el cuerpo. Una cosa que está vinculada a esto es ver el posicionamiento de nuestro cuerpo. Si trabajamos virtual o presencialmente, cómo nos sentamos, porque tenemos que sostener una situación que parece siempre la misma.

Uno de los problemas es que el terapeuta no escribe, no registra la sesión porque, como son todas iguales, no lo hace. Uno debe anotar o registrar para no desahuciar al paciente. Con un niño neurótico que simboliza es más fácil armar la entrevista; juega, dibuja, ya tenés el material. ¿Qué hacer con el niño que no dibuja, no hay lenguaje? Una de las claves es ir viendo cómo diferenciar ese mundo monótono y repetitivo. Al decir de Bion, si uno cambia de perspectiva, aquello que es caótico se vuelve más coherente o tiene más existencia. La clave es cambiar de perspectiva, pero no solamente de espacio físico, sino de mirada. Cómo miramos al niño, cómo miramos a la familia, y esto es clave para no desahuciar. Si siempre miramos lo mismo, estamos contagiados afectivamente. Me indiscrimino y siento el aburrimiento, el cansancio y quiero que la sesión termine porque me harté.

El furor curandis, que sería lo opuesto al desahucio, pasa mucho en profesionales jóvenes, no tanto en los analistas con más experiencia. Está la fantasía de que hay que hablar mucho con la familia, entonces te dicen: «La voy a derivar». Ese es otro tema: hay mucho dolor en la familia, pero no hay que derivar en la primera etapa; nosotros somos como el médico de familia, somos nosotros el representante del niño en la psicoterapia. Después, si es necesario derivar, la familia te lo va a pedir: «Bueno, Jorge, es hora de que yo haga una terapia». A veces hago sesiones con la madre, pero no es una terapia paralela, es una extensión. Derivar es una expulsión, es castrarlo, abandonarlo. Muchos terapeutas jóvenes se angustian y derivan o viven el furor curandis de creer que va a poder. Tenemos que aceptar que hay obstáculos y hay algo de la realidad. 
En el texto Discapacidad: reflexiones psicoanaliticas e intervenciones posibles. Familias-subjetividad-terapeutas afirmas que la construcción del vínculo terapéutico es una tarea compleja debido a la interferencia de elementos traumáticos, tanto en el paciente como en su familia. El paciente con discapacidad despliega múltiples embates a la capacidad de resistir del técnico, quien, contratransferencialmente puede verse oscilando entre la desesperanza, la apatía y la somnolencia. ¿Podríamos buscar pistas de anticipación y rescate?

En esta clínica hay que pensar en estrategias de intervención, hay que formarse y hay que reflexionar constantemente. A mí me enriquece mucho la formación académica, por eso dirijo tres formaciones de posgrado en discapacidad. Cuando ingresé a ASAPPIA, hace treinta años, pude formar y fundar el área de Discapacidad, pero era raro que un psicoanalista quisiera trabajar en este campo; había mucho cuestionamiento, no desconfianza. No entendían y yo decía que crear un espacio de seminario, de formación, nos rescata porque uno queda muy impregnado. Y en esta clínica más. Por eso, las presentaciones ayudan mucho. Cada uno encuentra la vía. Realmente, la creatividad en la formación y en otras cuestiones, así como tener recursos propios para manejarse en el campo de la discapacidad, ayuda mucho.

La consideración del proceso adolescente con discapacidad plantea nuevos desafíos. ¿Cómo favorecer la experiencia de autonomía y el autovalimiento?

Esto es muy interesante, porque se habla mucho del autovalimiento y de la autonomía, pero de lo que tenemos que hablar es de la autonomía psíquica y de la autodeterminación como expresiones del deseo, de la subjetividad y de la capacidad de elegir del adolescente con discapacidad. 
Un niño puede bañarse, comer solo; a pesar de su retraso, podría hacerlo. Hay familias que van discapacitando al niño porque lo siguen asistiendo en las actividades de la higiene o de la alimentación. La diferencia con la autodeterminación es la subjetividad en relación con el deseo. No hay autonomía si no hay deseo. Esto quiere decir que el niño logra la autonomía no solo porque el padre habilita, sino porque el niño desea la autonomía.

De mi experiencia con jóvenes con discapacidad, recuerdo particularmente un caso. Luego de la entrevista con los padres, tocan timbre y escucho la voz de la mamá, que dice: «Pablito» (joven que tenía entonces veinticinco años) y yo, que soy bravo, respondo: «No escucho la voz de ningún Pablito, escucho la voz de la mamá; no espero a ningún Pablito, espero a Pablo». Todo por el portero eléctrico. Y la madre dice: «Pablo, contestá, porque, si no, Jorge no nos va a atender». Más allá de la anécdota, esta era una consulta debida a que el joven iba a empezar a trabajar. Le digo a la madre que lo que me preocupa es que lo siga llevando en coche y me responde: «¿Y qué problema hay? Yo lo podría llevar a trabajar porque me ocupo siempre de él». Ahí está lo de para toda la vida. Cuando indago en el joven, a ver si había deseo, me dice: «¿Por qué voy a andar en colectivo? A mí me gusta que mi mamá me lleve». Había que lograr que el joven tuviera deseos de ser autónomo, no hay una ley que diga: «Vos tenés que andar en colectivo».

Ahí trabajo con la terceridad. Si la familia no está en condiciones de enseñarle a viajar en colectivo, tenemos que incorporar a un acompañante, un asistente, y trabajar en equipo para que el chico salga a la exogamia. Vivían en Buenos Aires, en un lugar con mucha conectividad. Más allá de las inseguridades, yo le dije a la madre que, si lo iba a llevar a trabajar, no le veía buen pronóstico. La madre quedó impactada. Era muy interesante porque el joven luchaba entre la autonomía y la dependencia 
materna, porque estaba muy cómodo en un apego desconectado y en su beneficio secundario de ser un bebé para toda la vida.

En la clínica de la discapacidad se ve mucho que la autonomía fracasa cuando está posicionada en un bebé para toda la vida. Entonces, hay que rescatar con la ley paterna o la terceridad. A veces prefiero poner acompañante y no dar tantas sesiones, no se soluciona con más sesiones. Hay terapeutas que se confunden y piensan que sumando sesiones logran autonomía. Hay que trabajar ese borde entre la casa y el afuera. Ahí podremos ver si pasa de la autonomía a la autodeterminación, que él tenga deseo, que él tenga ganas. Si no hay deseo de autonomía, por más terapeuta que haya, no se logra.

Con las madres trabajo los miedos, los riesgos. Por ejemplo, este joven tenía problemas expresivos. El miedo era de tipo: «¿Y si no lo entienden?». Una vez, le dije: «Mire, capaz que es fuerte lo que le voy a decir, ¿usted sabe la cantidad de gente sin saber leer o comunicarse que viaja en colectivo?». Fue fuerte porque su hijo no estaba en esa situación, no había llegado a la lectoescritura dado su retraso mental, pero se le podía enseñar a trasladarse en colectivo siempre y cuando él tuviera ganas.

Pero a veces es al revés: el joven tiene deseo y la familia no. «Vos lo estás convenciendo - me dijo una madre-. Él me habla, me muestra las monedas, quiere ir en colectivo.» Y mi respuesta: «Bueno, nosotros estamos trabajando para que sea grande, los grandes suben a un colectivo, a un subte».

\section{¿Cómo profundizar en el concepto de economía pulsional devastada desde adentro del paciente con discapacidad?}

Esto es muy interesante y tiene que ver con el concepto de que el trauma no es exterior, sino interior y puede estar devastado por los factores biológicos. Por ejemplo, un paciente que tiene convulsiones muy 
seguido porque presenta una epilepsia temprana, muy medicado, muy controlado, tiene ahí un componente biológico como una marca. En consecuencia, él está devastado todo el tiempo por el adentro, no por el afuera. El trauma es interior-exterior. ¿Qué pasa cuando un niño o un adolescente tiene dolores por su patología motora? Una atrofia muscular, una distrofia, yo digo que el cuerpo duele lo real.

Entonces, de alguna manera hay que trabajar la fantasmática, cómo irrumpe el dolor, cómo irrumpe el ataque epiléptico. A veces hay aura, a veces no, el dolor irrumpe. En esos casos, les pregunto: «¿Qué hacés cuando te duele?». Por poner un ejemplo, una paciente me dijo que el piso la calmaba y — hablando de lo teatral - yo me tiré al piso. La paciente se sorprendió, era una adulta que además venía con los bastones canadienses. "¿Qué hacés?», me preguntó. «Bueno, si vos estás tranquila en el piso, yo te acompaño desde el piso», porque parecía que el piso duro le daba fortaleza al cuerpo blando; Tustin habla mucho de cuerpo blando y cuerpo duro. Ella quedó muy impresionada, toda la terapia fue en el piso. «Aprovechá ahora porque no sé si cuando sea grande me voy a poder tirar», se acuerda siempre del chiste que le hacía. Ella se organizaba tirada en el piso duro, le hacía bien a los huesos, a los músculos; y después de eso, podríamos decir que nunca estuvo molesta con el cuerpo. Decía: «Lo voy a utilizar en otros lados, que todos se tiren al piso» y yo contestaba: «Bueno, no sé si vas a poder lograrlo, no sé si te vas a encontrar con otro terapeuta loco como yo en la vida». Ella trabajaba en una oficina, difícil.

Tú afirmas reiteradamente que la desvitalización proviene de lo intrapsíquico porque existe una relación entre la economía pulsional y la vitalidad anímica. También dices que permea la contratransferencia. Yo lo recuerdo como una somnolencia, como la escena temida. 
Uno desea que no se le cierren los ojos, la contratrasferencia en el cuerpo. ¿Qué denuncia la frecuente queja de aburrimiento?

Del aburrimiento del paciente, de la persona con discapacidad, hablo mucho en el libro Discapacidad..., hay un capítulo específico al respecto.

Ese embate pulsional en el cuerpo, ese tiempo paralizado, ese sentir que no pasa más la sesión, que parece que nunca termina. Y la queja del paciente. El aburrimiento es una forma de estar en el mundo. Es un posicionamiento, no poder investir el mundo y una forma de estar ahí, en ese mundo. Ahí hablo del aburrimiento como un equivalente depresivo, tal como lo plantea Melitta Sperling. Hay muchos estados de tristeza, pero son tristezas no neuróticas, tristezas no ligadas, no cualificadas, diríamos. Y no pasa porque el pibe se entretenga y lo llenemos, porque ahí es cuando la madre lo entretiene y le suma muchas cosas; tenemos que buscarle un sentido. Yo hablo del estado envidioso del otro, de lo que tiene, como un ataque a la producción y a la actividad, de alguna manera. Es un tema bien complicado, el aburrimiento produce hastío en el terapeuta. Es muy complicada la cosa quejosa, como una situación de ponerse en víctima de alguna manera.

¿Las crisis de violencia adolescente no denuncian la experiencia de sentirse violentado?

Sí, son violencias cruzadas entre la violencia pasiva y la denuncia activa. Siempre en la crisis del adolescente con discapacidad, siempre, lo que está en juego es la sexualidad no hablada, no verbalizada. Si bien la podemos tomar en cuenta en cualquier clínica, de la sexualidad en discapacidad no se habla hasta que estalla. 
Hablas mucho de eso: de que hay un pudor en el terapeuta, como que de esto no se habla y de que en las supervisiones te paras en este punto y dices que hay que profundizar más el acercamiento.

Claro, el terapeuta tiene que ser activo y creativo. Ante todo, activo y no esperar. No es un psicoanálisis en el que haya que esperar, hay que ser activo, sin bajar línea, que se puede interpretar sin encuadrar. A veces los colegas en formación me dicen: «Bueno, pero vos a veces te ponés muy directivo». A veces a los padres hay que despabilarlos porque pasa el tiempo y el paciente puede estar cinco años en terapia sin que hables nunca de sexualidad.

Cuando una joven de veintidós años con retraso mental tiene que ir al ginecólogo, sus padres me plantean: «¿Cómo ginecólogo, si ella es una beba?», a lo cual respondo: «¿Tiene desarrollo? Yo la veo desarrollada». Hay que ser cuidadoso porque, si no lo somos, la familia se confunde. Yo veo una mujer ahí, con rasgos infantiles, regresivos, pero una mujer al fin. Entonces me dicen: «Pero la terapeuta anterior, que era mujer, nunca me dijo nada de todo esto», y yo aclaro que no sé lo que pasó allí, que yo no me meto, pero que tiene que ir al ginecólogo. Los padres insisten y agregan que ella no tiene relaciones. Entonces, le pregunto a la madre si ella sí va al ginecólogo, a lo que me dice que a veces no «hay tiempo con estos hijos». Indago la salud en la familia, me pongo en el lugar de médico y pregunto cuánto hace que no van al médico los adultos.

A veces las familias no tienen tiempo de ir al médico y se generan descuidos en la salud. No me refiero a ahora, en pandemia; ya antes pasaba, independientemente de la facilidad de acceso a la atención sanitaria. Lo que planteo es que en la violencia queda la sexualidad silenciada. Y eso es violencia también. Una forma de violentar al adolescente es desconocer la cuestión del cuerpo, de los estímulos, de la excitación. Durante la pandemia recibí - y sigo recibiendo- muchas consultas por jóvenes 
con discapacidad, con retrasos leves, que tienen mucha furia y presentan ruptura de objetos en la casa. Y cuando pregunto si este síntoma es pandémico, me dicen que no, que antes lo hacía, pero que ahora hay mucha repetición y están muy asustados. Después es importante ver si hay que medicar, si hay que consultar con un psiquiatra, porque la furia puede ser muy riesgosa; pero cuando empiezo a hablar de la sexualidad los padres dicen que es un tema en el que ellos tienen miedo de indagar. "Yo sé que él se toca, está mucho tiempo en el baño, pero nosotros no hablamos porque es tan especial él».

Tenemos que asesorar a la familia sobre cómo poder hablar. Porque la violencia es la expresión de un sufrimiento que está callado. Es violento el adolescente porque está violentado en el silencio familiar. La sexualidad es un derecho. "Yo no sé si puede tener relaciones», me dicen, pero habría que ver por qué no podría tener relaciones, hay que ver con quién, cómo, hay que hacer preguntas muy cuidadosas. Los padres plantean: "Yo no quiero que pague por una mujer, una prostituta», pero no se trata de eso, sino de su derecho a su propia sexualidad.

Tenemos que poder plantear la importancia de cuidar su sexualidad como cuidamos la de cualquier hijo que va creciendo, al que uno le habla. Porque después, cuando la familia empieza a hablar o yo a indagar, el joven ya se recorrió un montón de videos, ya estuvo por todos lados y ahí le puede contar a la familia qué está haciendo. A lo mejor estuvo chateando en foros en los que no sabemos con quién se vincula, incluso con menores.

Insisto, en definitiva, en la violencia como un representante. Pueden ser violencias pasivas, que la familia lo violente. Por ejemplo, en pandemia hubo mucho duelo, muchas muertes por familiares, y una forma de violentar al adolescente es no hablar de que la abuela se murió, que no sigue internada. Entonces, le planteo a la familia que él percibe todo esto, que él sabe que algo pasa. «No, ¿cómo va a saber?». Y yo enfatizo en que 
él percibe algún dolor y en que es importante que hablen de que la abuela murió, de que no está internada. Porque para ellos es un gran esfuerzo, incluso disimular el dolor, pero para él es un trabajo psíquico doble: sabe que algo pasa en el ambiente, pero que no está dicho. Cuando la familia lo logra comentar, el niño o adolescente dice que ya lo sabe y la familia se impacta. Igual que en otros casos, el pibe queda muy arrasado. Esa es una forma de ser violento con el hijo: la violencia invisible, no informar sobre la realidad. Los padres están preocupados de que escriba, de que se bañe, pero no le explican que murió la abuela.

Tú haces importantes aportes sobre el vínculo fraterno y sobre la subjetividad del hermano sano, y enumeras los riesgos psicopatológicos más frecuentes. ¿Podrías desarrollar o ejemplificar algún estado de riesgo en los hermanos sanos?

El vínculo fraterno y la subjetividad del hermano sano es importantísimo, porque el hermano sano es dejado por «sano» y es enorme la culpa que siente, la angustia, la sobreexigencia y demás.

El gran riesgo son los excesos del hermano por compensar la falta de la casa: la sobreadaptacion, el falso self del hermano. El hermano está exigido todo el tiempo. O identificado, como también lo digo, paralizado por culpa. «¿Cómo voy a tener un logro si mi hermano no va a poder ser médico nunca?», «Mi hermano nunca se va a poder casar». A estos planteos yo respondo: «Quizás no se case, pero puede tener un vínculo afectivo, ¿por qué no? No sabemos». Del otro lado: «¿Mi hermano?, ¿una novia? ¿Puede tener?». Y yo: «No sé, ¿por qué decís que no?».

A modo de cierre: ¿cómo intervenir?, ¿cómo favorecer la esperanza? 
La esperanza en este campo estaría dada por cuánto la familia pudo enseñarle a ser autónomo. Si la familia le enseña a ser autónomo, hay esperanza, hay autonomía de discriminación del rol y de los vínculos. La esperanza tiene que ver con la capacidad que construyó la familia para que la persona con discapacidad tenga algo. Lo pudo aprender con respecto a su realidad. No me gusta la palabra techo, pero hay realidades. La esperanza se relaciona con la capacidad de ser feliz — aunque esta palabra está muy cuestionada en el contexto del capitalismo y atravesada por cuestiones ideológicas - la capacidad de disfrutar de la vida y de que el niño o el adolescente con discapacidad pueda elegir. La autodeterminación es subjetividad, deseo y elección. Elegir.

El otro día una familia estaba muy mal porque decían que su hijo quería hacer teatro, «pero ¡no habla!, jestá callado!». Lo que tenemos que hacer, en estos casos, es buscar el mejor lugar, un lugar donde el profesor sea continente. Pero que no le expliquen tanto, que lo conozca, que elija. Nosotros trabajamos en la terapia para que él eligiera. Si quiere hacer teatro, ¿por qué no va a poder hacer teatro? Tiene derecho. «No lo queremos frustrar», pero la frustración es que no lo haga; ahora estamos en la búsqueda.

La esperanza es que pueda elegir algo: derecho a elegir.

\section{En un momento dices «la posibilidad de ser genuino»...}

Claro, que no sea una prótesis, si no, estos pibes están como en un falso self, sobreadaptados, y lo que hacen no es genuino, es falso, y lo hacen por el deseo materno. Acá hay que trabajar mucho el narcisismo de los padres, cómo correrse de ese narcisismo y reconocer que su hijo puede elegir y que, aunque vaya un mes, dos meses, ya lo verán.

A veces está la cuestión de arruinar el proyecto del hijo, por eso hay que trabajar en familia. ¿Por qué nosotros disfrutamos tanto de la 
profesión? Porque es algo que nos apasiona y encontramos ahí nuestra identidad profesional, intelectual, de acompañar el dolor. Una persona con discapacidad ¿por qué no lo puede encontrar? Por ejemplo, es muy habitual — hablando de esperanza y expectativa - que los adolescentes con discapacidad aprendan cocina en los famosos talleres de cocina de las escuelas y centros de día, pero después, en la casa no los dejan porque se pueden lastimar, pueden incendiar la cocina. Ahora en pandemia, una de las cosas que trabajé con los familiares fue cómo lograr que lo que hacían afuera lo hicieran en la casa. «Ustedes tienen que lograr que eso que hacía afuera y le gustaba lo haga en casa», pero responden que no. Y yo insisto: «Pero la cocina no es de ustedes, es de todos».

Empezamos a ver que eran los miedos maternos que no lo dejaban elegir. Es cierto, podía hacer un zafarrancho, cortar media papa, había riesgos, había que asistirlo. Se le podía preguntar al tallerista de cocina cuáles eran los puntos flojos que había que cuidar. Lo que yo quería fundamentalmente era saber lo que el adolescente sabía hacer. «Hago pan», y yo: «Qué aburrido, ¿siempre pan?». Y la madre: «¿Cómo le dice eso a mi hijo?». «Tiene que salir de la monotonía, debe haber aprendido algo más», devuelvo yo.

El adolescente debía estar en la cómoda, quería hacer siempre pan, por lo que la madre tenía cinco quilos de pan todos los días en la casa para no dejar que se frustrara. Así la familia fomenta el ritual. Comento: «Seguro habrá aprendido a hacer otras cosas, pizza, galletitas», y el chico: «Sí, yo hago pizza, hago galletitas, pero mamá no quiere que haga galletitas». Entonces empezamos a trabajar esto de lo dulce, qué es lo dulce, la galletita como el símbolo de la ternura. Interpretaba que había que ver cómo la madre le habilitaba la ternura.

Ahora hace diez quilos de galletitas por día, todo el tiempo galletitas, porque se pone obsesivo y compulsivo. Empezamos a hablar de donaciones y el adolescente, con el barbijo puesto, va a llevarle a la gente que 
lamentablemente tenemos en la calle. Está haciendo una fusión interesante, el tema es que quiere charlar, pero pudimos lograr hacer algo y con un lazo social. Después fuimos, también, a una parroquia. En fin, eso sería la esperanza: ubicarlo en el mundo.

Son muchos años trabajando con la discapacidad y son muchos tus recursos. Tu estilo propio, desdramatizando. Tenemos que agradecerte la generosidad y la disponibilidad para este encuentro, que nos estimula a continuar trabajando y produciendo.

Es una clínica que agota también. Hay momentos en los que estoy cansado, pero este encuentro me revitaliza. Poder acordar y ver el entusiasmo de ustedes por el libro. Me fascina -en el buen sentido de la palabra- lo que significó para ustedes. Además, AUDEPP es una institución que quiero mucho, donde está el afecto de queridas y queridos colegas de tantos años.

Terminamos este encuentro con la esperanza, porque la utopía es nuestra brújula y, en especial, con las personas con discapacidad: no perder nunca la esperanza. 